\title{
The research on collaborative optimization of emergency human resource allocation
}

\author{
Qilin $\mathrm{Li}^{1, *, a}$, Chuanliang Jia ${ }^{1, \mathrm{~b}}$, and Jiu $\mathrm{Su}^{1, \mathrm{c}}$ \\ ${ }^{\mathrm{I}}$ School of Management Science and Engineering, Central University of Finance and Economics, \\ Beijing \\ acdliqilin@163.com, ${ }^{b}$ cnbjjcl@163.com, ${ }^{c}$ sujiesu@126.com
}

\begin{abstract}
On aglobal scale, the occurrence of different types of emergencies has had a tremendous impact on the economies and people's lives. The optimization of emergency human resource allocation is increasingly important. This paper gives full consideration to the control targets of each fire rescue points and the demands of both demand points and potential demand points. We build an emergency human resource allocation model and optimize it through the collaborative optimization. This paper finally carried on the case analysis to verify the feasibility of the model. The model better simulates the reality and can be referred by some government officials in some emergency cases.
\end{abstract}

\section{Introduction}

With the process of globalization and modernization entering into a period of generalization and deepening, human society has not only acquired countless opportunities, but also has undergone numerous risks and tests. The trend of social pluralism has caused the occurrence of mass incidents in modern society, and the emergency management has become a hot topic in the world. The demand for materials and human resource is explosive in emergency management, and a large amount of demand has raised higher requirements for human resource allocation. Whether the allocation of human resources is effective is the core key of the emergency management.

Emergency human resource allocation plays an important role in emergency management. Mohsen A. Jafari (2008) considered the configuration of medical personnel in emergency situations and proposed a solution to the allocation of limited human resources. Peng Yi and Xu Jianghong (2010) analyzed the current situation and shortage of emergency human resources in China, emphasized the importance of human resources in the emergency management and put forward corresponding solutions. Cao Jie(2011) studied emergency human resource management from the resource support, guarantee system and emergency human resource classification.

This paper takes the actual situation of the work of emergency management into consideration. Taking fire disaster as an example, we suppose the location of the demand points have been confirmed within a certain range of a city. Under the situation of limited human resource, the location of the emergency incidents requires multiple fire points to

*Corresponding author: cdliqilin@163.com 
send emergency personnel to rescue together. However, it is necessary to study the optimization of emergency human resource with the consideration of the potential possibility for similar emergencies in other regions. To make the rescue work convenient and fast, fire points should be fixed and should not be relocated. In this paper, we study the human resource allocation of fire stations and the suggestion of the optimization is of significant reference value to similar incidents.

\section{The theoretical basis of emergency human resource allocation}

\subsection{The problem description}

Taking a city as the study area, we divide it into several small areas which need rescue service. In order to simplify the problem, we further consider the small areas as demand points and assume an area broke out a fire at a time. The fire stations that can participate in the rescue are fixed and known.

For any fire incident, the demand for fire personnel is related to the situation of the fire. If the fire had not yet developed into a larger fire, the fewer firefighters needed to be deployed. But the firefighters are limited, a certain amount of fire fighting force need to be sent to a small fire. With the spread of fire, he demand for personnel will rise as the disaster worsens. In this paper, we assume that the demand for personnel will exceed the lower limit. The fire points need to save some fire fighters in response to the demand of other potential demand points when allocating human resource.

So the fire points need a certain amount of human resources for potential demand points. This part of the staff can arrive at the scene to rescue in time, and to stop the fire as soon as possible. Therefore, in the face of major emergencies, rescue work often requires the cooperation of multiple fire points to complete control targets successfully. In the study of this problem, the time of emergency personnel's arrival is preferred consideration. For the other areas of potential fire, we can determine occurrence probabilities, and consider the potential demand of various areas according to historical data.

\subsection{The description of collaborative optimization method}

Assuming that the system design problem can be decomposed into Nsub-subjects, the optimization process of collaborativeoptimization method can be described in the following mathematical expressions:

The system level is defined as:

$$
\begin{gathered}
\min F(Z): \\
\text { s.t. } J_{i}^{*}(z)=\sum_{j=1}^{s_{i}}\left(Z_{j}-X_{i j}^{*}\right)^{2}=0 \\
i=1,2, \ldots n
\end{gathered}
$$

$Z$ is the system-level optimization design vector; $Z_{j}$ represents the $\mathrm{j}$-th system design variable; $S_{i}$ is the number of design variables for the discipline $i ; X_{i j}^{*}$ represents the optimization result of the $\mathrm{j}$-th design variable for the discipline $i$.

The discipline level is defined as: 


$$
\begin{gathered}
\min J_{i}\left(x_{i}\right)=\sum_{j=1}^{s_{i}}\left(x_{i j}-z_{j}^{*}\right)^{2} \\
\text { s.t. } c_{i}\left(x_{i}\right) \leq 0
\end{gathered}
$$

$x_{i}$ is design vector of discipline $i ; S_{i}$ is the number of design variables for the discipline $i ; x_{i j}$ represents the $\mathrm{j}$-th design vector of discipline $i ; z_{j}^{*}$ represents the expectation of the j-th design vector that system level allocated to the discipline level. $c_{i}$ $\left(x_{i}\right)$ is the constraint of subject level.

\section{The collaborative optimization model of emergency human resource allocation}

Suppose there are $\mathrm{N}$ urban areas, one of which has a fire, and the rest of the N-1 areas are likely to be in fire at any time.The human resource layout of the fire points in a city has been determined and firefighters need to be deployed to respond to the rescue work. At the same time, the fire points need to consider the fire probability in the other $\mathrm{N}-1$ area and save some human resource to ensure the timely rescue of the potential area.

To build the model, we firstly set the parameters as follows:

- There are $\mathrm{m}$ fire points where $i=1,2, \ldots m$;

- There are $\mathrm{n}$ areas where $j=1,2, \ldots n$; To make the model simple, we assume the onfire location $\mathrm{j}=1$ and other potential location $j=2, \ldots n$;

- Fire stations $i$ own $q_{i}$ emergency personnel where $i=1,2, \ldots m$;

- The area of fire needs $r_{1}$ firefighters;

- The fire station $i$ has sent $x_{i 1}$ firefighters to the scene of the fire;

- The fire station $i$ sent $x_{i j}$ firefighters to the potential fire sites where $j=2, \ldots n$;

- $y_{i 1}$ is0-1 variable. If the fire point sends emergency personnel to the place where the fire has occurred, the value is 1 , otherwise it is 0 ;

- $y_{i j}$ is $0-1$ variable. If the fire point sends emergency personnel to the potential place where the fire is likely occurred, the value is 1 , otherwise it is 0 ;

- $t_{i 1}$ means the time that firefighters need from the fire point $i$ to the place where the fire has occurred

- $t_{i j}$ means the time that firefighters need from the fire point $i$ to the potential place where the fire is likely occurred where $j=2, \ldots n$

- $U_{j}$ represents the amount of human resource that is not met in each area

- $D_{j}$ means the latest time for each area $j$ to request for support. After that, the fire spread quickly, causing even greater losses and bringing more casualties to life 
- $\delta_{i j}$ represents the delaying time from the fire point to the area of demand. If the emergency fire personnel can reach the demand point before, then $\delta_{i j}=0$; Otherwise, there will be a delay and $\delta_{i j}>0$

- $p_{j}$ represents the probability of fire in each potential place. It can be obtained by historical data and the study of fire. It is in $[0,1]$

We build collaborative optimization model as follows.

The system level:

$$
\begin{gathered}
\min U_{1}+\delta_{1}+\sum_{j=2}^{n} p_{j}\left(U_{j}+\delta_{j}\right) \\
\text { s.t. } \sum_{i=1}^{m} x_{i 1}+U_{1} \geq r_{1} \\
\sum_{i=1}^{m} y_{i 1} \geq 1 \\
\sum_{i=1}^{m} y_{i j} \geq 1(j=2,3, \cdots, n) \\
0 \leq t_{i j}-\delta_{i j} \leq D_{j} \sum_{i=1}^{m} y_{i j} \\
x_{i j}, U_{j}, \delta_{i j} \geq 0
\end{gathered}
$$

The discipline level:

$$
\begin{gathered}
j=1,2, \ldots n \\
\sum_{i=1}^{m} x_{i j}+U_{j} \geq p_{j} r_{j} \quad(j=1,2,3, \cdots, n) \\
\sum_{j=1}^{m} x_{i j} \leq q_{i} \\
\delta_{i j} \leq \sum_{i=1}^{m} y_{i j} M \\
y_{i j} \in\{0,1\}, \quad(i, j=1,2, \cdots, n) \\
x_{i j}, U_{j}, \delta_{i j} \geq 0
\end{gathered}
$$

Formula (6) is the objective function of the system level of emergency model. It minimum the sum of the delaying time that firefighters need from fire points to demand points under certain possibility and the sum of emergency rescue resource which could not meet the demands. Formula (7) means the human resource of all fire points should meet the 
demand of the fire area. Formula (8) and (9) ensure at least one fire station sent or saves emergency personnel for the demand or potential demand points. Formula (10) means, if the deadline is missed, the needed time from fire station $i$ to demand point $j$, the delaying time and the deadline should meet certain requirements. Formula (12) represents the target function of each fire point. Each fire point has its own human resource demand and the minimum delay time (fire effectiveness). Formula (13) and (14) represent the sum of the emergency personnel reserved for fire points should be as much as possible to meet the demand of the potential occurrence. Formula (15) is the constraint that the emergency personnel can provide the maximum demand human resource. Equation (16) means that the value can only be 0 or 1 .

\section{An application example}

We use an example to illustrate the feasibility of the collaborative optimization model of emergency human resource. Suppose that there are 4 fire points in a region, respectively $I_{1}$, $I_{2}, I_{3}, I_{4}$. And three crowded public places may be in fire, which are demand points $J_{1}$, $J_{2}, J_{3}$.There has been a fire in public place $J_{1}$. And two other public places will fire with different probabilities at the same time or not.

We will consider the deployment plan of emergency human resource. The distribution of fire points and demand points is shown in figure 1

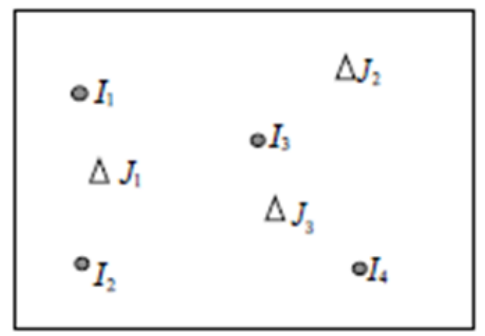

Fig.1. The distribution of fire points and demand points

The personnel quantity $q_{i}$ of each fire point is randomly generated four integer values between 20 and 40. The demand $r_{j}$ of each demand point is randomly generated three integer values between 20 and 40. The fire possibility of demand point $J_{2}$ and $J_{3}$ is randomly generated two decimal numbers between 0 and 1 . The needed time and the latest arrival time from each fire point to each demand point is respectively determined by $[10,90]$ and $[30,50]$ as an integer. The parameters are set as shown in table 1

The parameters are taken into the model, and table 2 is obtained through MATLAB

Table 2 shows the fire points needs to allocate the number of personnel, and the fire points save some emergency human resource for the potential demand with certain probability. According to table 2 and setting parameters, we can draw deployment diagram which is shown in figure 2.

As we can see from figure 2 , fire points $I_{1}, I_{2}, I_{3}$ can meet the human resource requirements of the demand point $J_{1}$, which has been a fire. And fire points $I_{1}, I_{3}$ can meet the human resource requirements of the demand point $J_{2}$, which is likely to fire. fire 
points $I_{3}, I_{4}$ can meet the human resource requirements of the demand point $J_{3}$, which is likely to fire.

Table1. The parameters setting

\begin{tabular}{|c|c|c|c|c|}
\hline$\left(t_{i j}\right)$ & $J_{1}$ & $J_{2}$ & $J_{3}$ & $q_{i}$ \\
\hline$I_{1}$ & 20 & 50 & 70 & 20 \\
\hline$I_{2}$ & 30 & 75 & 60 & 25 \\
\hline$I_{3}$ & 35 & 40 & 20 & 36 \\
\hline$I_{4}$ & 75 & 55 & 35 & 26 \\
\hline$D_{j}$ & 35 & 50 & 45 & \\
\hline$r_{j}$ & 28 & 20 & 35 & \\
\hline$p_{h}$ & 1 & 0.05 & 0.02 & \\
\hline
\end{tabular}

Table 2. The basic model results

\begin{tabular}{|c|c|c|c|}
\hline$\left(x_{i j}\right)$ & $J_{1}$ & $J_{2}$ & $J_{3}$ \\
\hline$I_{1}$ & 10 & 2 & 0 \\
\hline$I_{2}$ & 12 & 0 & 0 \\
\hline$I_{3}$ & 6 & 8 & 18 \\
\hline$I_{4}$ & 0 & 0 & 10 \\
\hline & & & \\
\hline
\end{tabular}

Fig 2. The relationship map of the deployment

\section{Conclusion}

In the case of emergency rescue, a reasonable allocation of human resources should be required to respond to emergencies. In this paper, we optimize the human resource allocation through the collaborative optimization method by considering the fire target of the whole area and each fire point.We make a full consideration to the control targets of each fire rescue points and the demands of both demand points and potential demand points. We build an emergency human resource allocation model and optimize it through the collaborative optimization.Research shows that using collaborative optimization can meet both current and potential fire targets and save human resources. The conclusion canbe referred by some government officials in some emergency cases. 
As for the future scope, without considering the evolution of the fire situation, we should deeply modify the model in the future work. Also the number of fire points and demand points are less than the real situation.This limits the widespread use of the model.Further research can make the model more realistic.We should improve this model by considering more fire points and demand points and the multifarious change of the fire disaster.

Acknowledgment: This paper is supported by Program for Innovation Research in Central University of Finance and Economics

\section{References}

1. B. Balcik, B. M. Beamon. Facility location in humanitarian relief[J]. International Journal of Logistics Research and Applications, 2008, 11(2):101-121

2. Jiang Jingui, Liang Jingguo. Research on emergency management mechanism based on grid management [J]. Intelligence journal, 2008, 27 (6) : 26-28

3. Liang Xianyan, Wu Shuxian. Analysis on human resources in emergency management [J]. Management observation, 2008 (9) : 14-15.

4. Lu Na. Research on human resource allocation in crisis management organization [J]. Management, 2011 (1) : 102-102.

5. Ronald Klingler. Human Rights Management in Public Sector: System and Strategy [M]. Renmin University of China Press, 2001.

6. Peng $\mathrm{Yi}, \mathrm{Xu}$ Jianghong. Research on human resource management in emergency management [J]. Journal of Taiyuan urban vocational and technical college, 2010 (3) : $50-52$

7. Sun Ying. Research on resource distribution and scheduling model in emergency management of emergencies [D]. Graduate school of Chinese academy of sciences, 2008.

8. Wu Yufeng. Research on emergency human resource management in the context of public crisis [J]. Human resource management, 2014 (9) : 85-85

9. Chen Y L, Emergency D O. Emergency management of nursing human resourcedeployment when emergency department crowding $[\mathrm{J}]$. China Modern Medicine, 2013

10. Chu W H J, Lee C C. Strategic information sharing in a supply chain[J]. European Journal of Operational Research, 2006, 174(3):1567-1579..

11. Jafari M A, Golmohammadi D, Seyed K. Staff Management in Emergency Evacuation Preparedness and Response[J]. Journal of Homeland Security \& Emergency Management, 2008, 5(1):1254-1265

12. Lämmel G, Grether D, Kai N. The representation and implementation of timedependent inundation in large-scale microscopic evacuation simulations[J]. Transportation Research Part C Emerging Technologies, 2010, 18(1):84-98

13. Mete H O, Zabinsky Z B. Stochastic optimization of medical supply location and distribution in disaster management[J]. International Journal of Production Economics, 2010, 126(1):76-84

14. Wang F X, Ren J. Human Resources Optimization Allocation Model Based on Human Matching for Position[J]. Technology \& Innovation Management, 2011.

15. Yang Q, He G, Li L. Application of Genetic Algorithm on Human Resources Optimization[C]// International Conference on Computer and Communication Technologies in Agriculture Engineering(cctae 2010) (volume. 2010:160-163. 